\title{
Algoritmos racistas: a hiper-ritualização da solidão da mulher negra em bancos de imagens digitais
}

\author{
Fernanda Carrera \\ https://orcid.org/0000-0001-5024-0860 \\ Denise Carvalho" \\ https://orcid.org/0000-0001-7569-6127 \\ I - UFRJ \\ Rio de Janeiro (RJ), Brasil \\ II - UFRN \\ Natal (RN). Brasil
}

Resumo: Reconhecendo a importância das discussões a respeito dos algoritmos em mecanismos de busca e seus vieses possivelmente discriminatórios e racistas, este trabalho analisa três bancos de imagens digitais e seus resultados para as palavras-chave "family", "black family" e "white family". Com base no conceito de "hiper-ritualização" de gênero de Erving Goffman (1979), estuda-se aqui se a perspectiva imagética de família (mulher, homem, filho e filha) se aplica para o contexto negro ou, ao contrário, corrobora para a "solidão da mulher negra". Analisando comparativamente mais de 2.500 imagens, percebeu-se que as mulheres negras são mais representadas sozinhas com seus filhos do que as mulheres brancas; a palavra-chave "family" resulta em maioria expressiva de famílias brancas; e a pesquisa por "white family" apresenta mais resultados "infiltrados" de famílias negras como indício de racialização da pesquisa para o algoritmo de busca, que considera a branquitude como normativa e neutralidade.

Palavras-chave: algoritmos; bancos de imagem; racismo; feminismo negro.

Abstract: Racist algorithms: the hyper-ritualization of black women's solitude in digital image databases - Recognizing the importance of the discussions on algorithms in search engines and their possible discriminatory and racist biases, this paper analyzes three digital image databases and their results for the keywords "family", "black family" and "white family". Based on Erving Goffman's (1979) concept of "hyper-ritualization" of gender, this article studies whether the imagetic perspective of family (woman, man, son and daughter) applies to the 
black family context or, on the contrary, contributes to the "solitude of the black woman". Analyzing comparatively more than 2500 images, it was noticed that black women are more represented alone with their children than white women; the keyword "family" results in an expressive majority of white families; and the search for "white family" reveals more "infiltrated" results of black families as evidence of racialization of the exploration of the search algorithm, which considers whiteness as normative and neutral.

Keywords: algorithms; images databases; racism; black feminism.

\section{Introdução}

Os desafios trazidos pela inteligência artificial e pelas tecnologias digitais contemporâneas fazem emergir debates importantes sobre seus artifícios de produção e suas influências sobre as percepções e os comportamentos humanos. Nesse contexto, alguns estudos buscaram compreender de que forma aparatos tecnológicos atuais, como algoritmos, chatbots e mecanismos de busca podem ser discriminatórios e reproduzir associações estereotipadas e nocivas a respeito de gênero (DATTA, TSCHANTZ \& DATTA, 2015) e raça (LARSON et al, 2016), além de possibilitar tratamentos diferenciados baseados em geolocalização (MALBON, 2016). Este trabalho, portanto, busca dar continuidade a este campo de investigação, identificando padrões de resultado de mulheres negras em fotografias de bancos digitais de imagens. Sabe-se que estes bancos são fontes fundamentais para o mercado publicitário, para conteúdos digitais, como sites e blogs, e até mesmo para anúncios governamentais, sendo, portanto, essenciais para a construção do imaginário social a respeito dos corpos e dos sujeitos sociais.

O escopo teórico-analítico aqui escolhido reside inicialmente nos pressupostos de Erving Goffman, no livro Gender Advertisements. Publicado em 1979, o livro é um estudo de mais de 500 fotografias e ilustrações com o objetivo de apontar as hiper-ritualizações de gênero nas imagens publicitárias. No entanto, "de que mulheres estamos falando" (CARNEIRO, 2003, p. 50)? Entende-se que, ao falar sobre representação de mulheres de forma generalizada (analisando apenas anúncios veiculados no contexto norte-americano), Goffman negligencia especificidades que poderiam trazer resultados diversos, como a inserção das variáveis raça, classe e contexto geográfico-cultural.

Especificamente no contexto racial, os resultados de trabalhos anteriores mostram diferenças relevantes: mulheres negras não são comumente associadas à fragilidade, mas à força e selvageria (PLOUS \& NEPTUNE, 1997, p. 638), e são menos representadas na companhia de homens (COLLINS, 2000; JEWEL, 1993). Esse último dado, no entanto, pode ser interpretado como uma associação a "independência", como defendido em alguns trabalhos (BAKER, 2005), como pode ser um rastro discursivo potente sobre a solidão da mulher negra (SOUZA, 2008; PACHECO, 2008).

Assim, busca-se neste trabalho comparar as representações de mulheres negras e brancas em bancos de imagens digitais, com o intuito de identificar se há diferenças 
nos resultados de busca apresentados pelos seus algoritmos. Aqui, o objetivo é analisar especificamente a questão da independência/solidão no contexto da família, tentando responder: nestas imagens, são as mulheres negras apresentadas ao lado de homens na mesma proporção que as mulheres brancas? De que forma os resultados imagéticos sobre família e afetividade diferem e se assemelham aos resultados que mostram mulheres brancas?

\section{Ambiente digital, algoritmo e discriminação}

Em 2018, o livro "Algorithms of Oppression: How Search Engines Reinforce Racism"1" de Safiya Noble, ganhou importante notoriedade por desvelar de forma contundente os modos do racismo contemporâneo manifestados por resultados de busca. Analisando especificamente o Google, Noble mostra que as fórmulas algorítmicas que ditam os resultados das pesquisas, percebidas muitas vezes como neutras, objetivas e "infalíveis" (OSOBA \& WELSER IV, 2017), na verdade reproduzem e fortalecem uma estrutura racista e machista. Noble argumenta que, embora a empresa alegue que não pode se responsabilizar pelos seus resultados - uma vez que são um produto misto de relevância e popularidade advindas dos usuários, há pouca transparência a respeito do que direciona o algoritmo para estes resultados, em uma lógica corporativista de um intenso "capitalismo de dados" (MOROZOV, 2015), que reforça a necessária articulação política para a exposição e a denúncia (NOBLE, 2018).

Outros estudos contemporâneos apontam para os malefícios dos vieses algorítmicos, que influenciam nas decisões de automação em machine learning, inteligência artificial e chatbots, trazendo consequências fundamentais para a circulação dos signos e das informações entre sujeitos sociais. Osoba e Welser IV (2017) apontam para os vieses destes "agentes artificiais", muitas vezes respaldados pela atribuição aos dados e ao big data um poder quase religioso, místico, de previsão e deslumbramento - ou "dataism"2 (HARARI, 2017) - para sua utilização como catalisadores de tomadas de decisão extremamente relevantes para a vida de indivíduos. No entanto, não somente não há tais poderes nestes agentes artificiais, como, ao contrário, eles estão levando a desde resoluções racistas, reproduzindo construtos de neutralidade branca e tecnológica, como resume Tarcízio Silva (2019, p. 2) no conceito de "dupla opacidade", quanto sexistas, ao afetarem resultados de busca por ofertas de emprego (DATTA, TSCHANTZ \& DATTA, 2015), classificação de risco enviesada para empregabilidade e crédito (CITRON \& PASQUALE, 2014), a até mesmo previsões falhas e perigosas de reincidência criminal (LARSON et al, 2016).

O cerne da questão aqui exposta reside na percepção de que as dinâmicas de poder existentes são reproduzidas em ferramentas digitais que se propõem "disruptivas" (ADNER, 2002), perpetuando antigas ideologias e representações, além de negligenciar

\footnotetext{
1 "Algoritmos da opressão: como os mecanismos de busca reforçam o racismo" (tradução nossa).

2 Alguns traduzem como "dadismo". Ver https://www1.folha.uol.com.br/mercado/2017/05/1874301-capitalismode-dados-lucra-com-a-nossa-privacidade-por-enquanto.shtml
} 
novas narrativas e demandas sociais contemporâneas, como se fosse possível posicionar o ciberespaço como um espaço para a transcendência da raça, da classe e do gênero (HOBSON, 2008, p. 112). Admitindo que não há transcendência, mas, ao contrário, reprodução destas dinâmicas de poder e subjugação, faz-se necessária a exposição das lacunas e esforços em prol de sistemas tecnológicos e algorítmicos menos prejudiciais.

Em bancos de imagens, objeto de análise deste trabalho, essa estrutura de poder se manifesta tanto pelo tipo de imagens que são comumente expostas como resultados relevantes de um grupo social quanto pelo fato de que alguns grupos sequer são apresentados. O site Nappy ${ }^{3}$ e o Mulheres Invisíveis ${ }^{4}$ são alguns bancos criados para dar conta dessa lacuna de representação imagética. Enquanto o primeiro se propõe a apresentar imagens em alta resolução com indivíduos negros em situações cotidianas (como forma de conseguir burlar a falta de representação dos bancos de imagens tradicionais), o segundo oferece imagens de mulheres que geralmente são excluídas dos resultados de busca por imagens profissionais: gordas, transexuais, negras e lésbicas. Sendo assim, não somente os bancos de imagens tradicionais oferecem uma classificação de relevância que deve ser questionada, como as próprias escolhas de composição destas imagens parecem recorrer ainda a processos de hiper-ritualização de gênero, a que Goffman (1979) se referia, mas também, como aqui se pretende analisar, a possíveis hiper-ritualizações de raça.

\section{Goffman, hiper-ritualização e raça}

Em Gender Advertisements, Goffman conceitua a "hiper-ritualização" como um esforço imagético de reproduzir novamente as ritualizações de gênero que já acontecem na vida cotidiana (GOFFMAN, 1979, p. 4). Nesse sentido, descreve seis categorias que podem guiar a análise da representação de gênero nos anúncios: "relative size" (mulheres em geral são representadas em tamanho menor que os homens); "feminine touch" (atribui-se à mulher fragilidade e toques delicados); "function ranking" (homens como professores e mulheres como aprendizes nas mais diversas atividades sociais); "the family" (núcleo familiar composto por homem, mulher e dois filhos); "the ritualization of subordination" (comportamentos de subordinação associados à mulher, como dobrar joelho e cabeça); e "licensed withdrawal"5 (mulheres aparecem mais perdidas, desorientadas). De acordo com sua perspectiva, estas expressões representam uma concepção ideal dos gêneros e da estrutura relacional que engendram entre si.

No entanto, de que idealizações Goffman fala? Os trabalhos de Ford et al (1998), no contexto japonês, e de Wei (2010), na conjuntura chinesa, são alguns exemplos relevantes de aplicações em estruturas culturais diversas que transcendem os resultados

\footnotetext{
www.nappy.co/

http://www.mulheresinvisiveis.com/

5 Tamanho relativo; toque feminino; ranking de função; a família; a ritualização da subordinação; e licença para ausência (tradução nossa).
} 
goffmanianos restritos ao contexto ocidental da branquitude estadunidense. No contexto racial, especificamente, alguns estudos buscaram compreender se as relações propostas por Goffman se aplicavam ao contexto da mulher negra (BAKER, 2005; MCLAUGHLIN \& GOULET, 1999). De acordo com as autoras, outros estereótipos parecem representar um papel importante quando se cruza gênero e raça. Assim, embora estes trabalhos não discorram sobre os pressupostos específicos do feminismo interseccional (CRENSHAW, 2018; AKOTIRENE, 2018), uma vez que não consideram a classe como variável relevante nem mesmo articulam conceitualmente esta perspectiva teórica, há a concepção comum da problemática da generalização. Por exemplo, ideais femininos de afabilidade e delicadeza, que Goffman generaliza para toda e qualquer mulher, não estão relacionados às mulheres negras, que são representadas como antagonistas, agressivas e fortes (MCLAUGHLIN \& GOULET, 1999, p. 63-64).

Dentro deste campo de estudos, o trabalho de Christina Baker (2005) também se destaca quando afirma que os estereótipos midiáticos atribuídos às mulheres negras e brancas diferem substancialmente, uma vez que as imagens mais comuns associadas à mulher negra não acompanham a afabilidade e submissão que Goffman se referia, e, sobretudo, às mulheres negras são atribuídas as imagens que chama de "a matriarca", "Jezebel" e "Sapphire" (BAKER, 2005, p. 15). Isto é, "Jezebel" seria a representação da mulher negra sexualmente agressiva, animalesca; "a matriarca" seria a representação da mulher negra mãe, que detém mais autoridade em casa que os pais, ou são mães solteiras; e a "Sapphire" seria um produto da representação da matriarca, ao apresentar uma imagem de mulher independente e dominante, ameaçando os homens em seus sentidos de masculinidade.

No entanto, ao analisar estas representações e apresentar os resultados da sua pesquisa, Baker (2005) atribui duas relações causais que podem ser problematizadas, pelo menos, para o contexto da mulher negra. A primeira diz respeito à imagem da "matriarca", que a autora atribui a uma ritualização da pobreza ainda associada ao povo negro e, especificamente, ao desemprego dos homens negros, que forçaria as mulheres a assumir o papel de provedoras da família; e a segunda reside na relação direta entre a pouca representação imagética de mulheres negras ao lado de homens com o fator "independência", ignorando, assim, a problemática da solidão da mulher negra.

\section{Racismo, mulher negra e solidão}

O conceito de solidão da mulher negra é um desdobramento identificado na sociedade brasileira atual como resultado de um conjunto de elementos socialmente estruturados remanescentes do racismo moderno. De acordo com Elias (1985), o conceito de solidão, em diversas situações, está relacionado não apenas a pessoas isoladas socialmente, mas também à vivência de pessoas que não possuem significado afetivo 
em meio a outras que estão ao seu redor. Desde as décadas mais recentes do século XX, a miscigenação na sociedade brasileira tem sido desenvolvida como um projeto eugenista de embranquecimento populacional, impondo culturalmente aos negros e indígenas a insígnia dos indivíduos "primitivos a serem civilizados" (GROSFOGUEL, 2016, p. 39) e construindo para a branquitude a ideia de superioridade moral e intelectual, assim como de civilidade e progresso (SHUCMAN, 2014, p. 91). Sendo assim, a preferência dos homens negros por parceiras não negras no campo afetivo-sexual (AZEVEDO, 1955) se manifesta dentro dessa estrutura racial, que coloca a mulher branca, sobretudo, como "avalista" (CARNEIRO, 1995, p. 75), isto é, uma fiadora da existência do homem negro nos espaços sociais. Escolhê-la romanticamente, portanto, é um dos modos de sobrevivência do homem negro em busca de ascensão social, poder e menos experiências de opressão.

A esfera matrimonial assume, assim, uma carga simbólica capaz de associar os diferentes indivíduos a condições de mobilidade social previamente estabelecidas (AZEVEDO, 1955). Esta carga simbólica surge então, marcada por um conjunto de subjetividades estruturadas pela diferença com relação a etnicidade, raça e gênero (MOORE, 2000). É caso das mulheres negras (pardas e pretas), que são preteridas como possíveis candidatas a uniões estáveis, tanto com homens negros quanto brancos, perdendo espaço para mulheres de outros grupos raciais, compostos significativamente, por mulheres brancas (PACHECO, 2008; 2013), ficando, por vezes, reservadas a uma vida de celibato ou concubinato, perdendo as chances de casamento mesmo entre mulheres não negras pobres e com baixo grau de instrução (AZEVEDO, 1955).

Ao analisar os corpos das mulheres negras no contexto norte-americano, Bell Hooks (1995) afirma que a representação dos corpos destas mulheres nos períodos escravagista e pós-escravagista estava relacionada a apenas um corpo sem mente. Exemplo disso foi a utilização do corpo negro feminino para gerar novas crianças escravizadas, aliado à disseminação da representação das mulheres negras como hipersexualizadas para justificar os estupros durante a escravidão categorizando estas mulheres como 'desregradas'. Em paralelo a esta representação social da sexualidade da mulher negra, está a imagem de associação da mulher negra ao estereótipo de instrumento servil e que persiste até os dias atuais. Fatores como estes persistem no imaginário brasileiro sob as representações da mulher negra como a 'mulata' ou como a 'doméstica' (PACHECO, 2013).

Neste aspecto, de acordo com Pacheco (2013), como resultado destas representações sociais que perpassam raça e gênero, embora sexualizada, a mulher negra encontra-se fora do mercado afetivo, estando sua imagem reservada ao mercado do sexo e do trabalho. Moore (2000) afirma que mulheres negras, por exemplo, são classificadas como menos atraentes pelo fato de seu fenótipo, tom de pele e cabelo natural, estar dissociado de uma representação ideal de feminilidade. Este sistema de crenças está fundamentado sobre uma ideologia racista, que dissolve e volatiliza o ideal igualitário largamente difundido na sociedade moderna. 


\section{Hiper-ritualização da solidão da mulher negra nas imagens digitais}

Causado por múltiplos fatores, o preterimento afetivo à mulher negra, como visto, pode estar sendo perpetuado ainda na contemporaneidade pela produção e circulação das imagens midiáticas e digitais. Acredita-se que, não somente a produção imagética ainda segue o curso da hiper-ritualização (GOFFMAN, 1979) do imaginário social do que é ser mulher e negra (mulher sozinha disponível para exploração laboral e sexual), como as fórmulas algorítmicas priorizam este tipo de representação creditando a estas imagens estereotipadas o alto grau da relevância nos resultados de busca em bancos de imagens digitais.

Considerando que o fator solidão relaciona-se também à ausência de parceiros sexuais e afetivos, aqui, restringiu-se a análise à categoria "family", proposta por Goffman (1979), mas agora inserindo a variável raça na problematização e discussão dos resultados. Se, segundo o autor, a família nuclear em geral é composta por homem, mulher, filho e filha, seria essa a composição familiar no contexto negro?

\subsection{Metodologia e definição da amostra}

Foram escolhidos três dos principais bancos pagos de imagens digitais (Getty Images ${ }^{6}$, Stock Photos $^{7}$ e Shutterstock ${ }^{8}$ ), uma vez que são importantes fontes de recursos imagéticos no campo publicitário, comercial, jornalístico e governamental. Nos três bancos, foram analisados, no dia três de janeiro de 2019, os resultados das três primeiras páginas de cada busca, utilizando o filtro padrão do site (ordenar por relevância) ${ }^{9}$. Assim, no Getty Images, foram examinadas 180 imagens utilizando a palavra-chave "black family" e 180 imagens utilizando a palavra-chave "white family"; no Shutterstock, foram coletadas 311 imagens para "black family" e 319 imagens para "white family"; e no Stockphotos, 301 imagens para "black family" e 301 imagens para "white family". Dessa forma, analisouse 792 imagens para a palavra-chave "black family" e 800 imagens para a palavra-chave "white family", totalizando 1.592 imagens examinadas nessas categorias.

Importante destacar que a análise se baseou na presença ou ausência de homens no contexto visual da imagem, isto é, foram contabilizadas para a categoria de "mulheres sozinhas" apenas aquelas imagens que não apresentam nenhum indivíduo do gênero masculino. Sendo assim, imagens com duas ou mais mulheres, assim como mulheres com filhos sem presença paterna ou cônjuge, foram consideradas "mulheres sozinhas". Ademais, com o intuito de comprovação de hipóteses, foi realizada uma análise dos resultados para a palavra-chave genérica "family", no dia cinco de fevereiro de 2019,

https://www.gettyimages.com

7 https://stockphotos.com.br

8 https://www.shutterstock.com

9 Como a análise partiu das três primeiras páginas de resultados, cada site organiza um padrão quantitativo de imagens para cada página e cada busca. Por isso, os resultados em números de imagens variam. 
trazendo 300 imagens do Getty Images, 319 do Shutterstock e 301 do Stock Photos, totalizando 920 imagens analisadas dessa categoria. Ao todo, portanto, 2.512 imagens compuseram o estudo aqui apresentado.

\subsection{Hipóteses e Resultados}

\section{- Hipótese A:}

Quando se pesquisa por representações de famílias em bancos de imagens digitais, as mulheres negras aparecerão mais frequentemente sozinhas, sem a presença de uma figura masculina ao lado, do que as mulheres brancas, como evidência do preterimento afetivo e solidão da mulher negra.

\section{- Resultados:}

No banco de imagens Getty Images, das 180 imagens resultantes da palavra-chave "black family", 56 representavam mulheres negras sozinhas, totalizando 31,11\% dos resultados. Já no contexto branco, das 180 imagens resultantes da palavra-chave "white family", 33 representavam mulheres brancas sozinhas, totalizando 18,33\% dos resultados.

No banco de imagens Shutterstock, das 311 imagens resultantes da palavra-chave "black family", 28 representavam mulheres negras sozinhas, totalizando 9,00\% dos resultados. Já no contexto branco, das 319 imagens resultantes da palavra-chave "white family", 27 representavam mulheres brancas sozinhas, totalizando 8,46\% dos resultados.

No banco de imagens Stockphotos, das 301 imagens resultantes da palavra-chave "black family", 27 representavam mulheres negras sozinhas, totalizando 8,97\% dos resultados. Já no contexto branco, das 301 imagens resultantes da palavra-chave "white family", 14 representavam mulheres brancas sozinhas, totalizando 4,65\% dos resultados.

No total, portanto, das 792 imagens resultantes da palavra-chave "black family" nos três bancos de imagens, 111 representavam mulheres negras sozinhas, totalizando 14,01\% dos resultados. Já no contexto branco, das 800 imagens resultantes da palavra-chave "white family" nos três bancos de imagens, 74 representavam mulheres brancas sozinhas, totalizando 9,25\% dos resultados. Diante desses resultados, portanto, a hipótese foi comprovada (ver figura 1).

\section{Comparação entre representações imagéticas de mulheres brancas e negras sozinhas}

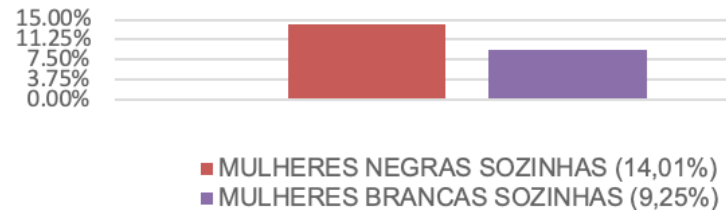

Fig. 1. Quadro comparativo de resultados entre mulheres brancas e negras sozinhas em bancos de imagens digitais. Fonte: Elaboração própria. 
Resolveu-se, ainda, comparar estes números com o contexto masculino, uma vez que homens sozinhos também foram encontrados como resultados das buscas. No entanto, os números puderam servir como uma corroboração do privilégio masculino branco. Isto é:

No banco de imagens Getty Images, das 180 imagens resultantes da palavra-chave "black family", 37 representavam homens negros sozinhos, totalizando 20,55\% dos resultados. Já no contexto branco, das 180 imagens resultantes da palavra-chave "white family", 18 representavam homens brancos sozinhos, totalizando 10,00\% dos resultados.

No banco de imagens Shutterstock, das 311 imagens resultantes da palavra-chave "black family", 11 representavam homens negros sozinhos, totalizando 3,54\% dos resultados. Já no contexto branco, das 319 imagens resultantes da palavra-chave "white family", 09 representavam homens brancos sozinhos, totalizando 2,82\% dos resultados.

No banco de imagens Stockphotos, das 301 imagens resultantes da palavra-chave "black family", 12 representavam homens negros sozinhos, totalizando 3,99\% dos resultados. Já no contexto branco, das 301 imagens resultantes da palavra-chave "white family", 06 representavam homens brancos sozinhos, totalizando 1,99\% dos resultados.

No total, portanto, das 792 imagens resultantes da palavra-chave "black family" nos três bancos de imagens, 60 representavam homens negros sozinhos, totalizando $7,57 \%$ dos resultados. Já no contexto branco, das 800 imagens resultantes da palavrachave "white family" nos três bancos de imagens, 33 representavam homens brancos sozinhos, totalizando $4,12 \%$ dos resultados. A comparação entre os resultados pode-se ver na figura 2 :

\section{Comparação entre representações imagéticas de homens brancos e negros sozinhos}

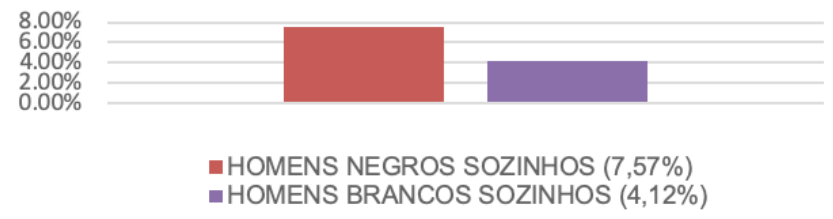

Fig. 2. Quadro comparativo de resultados entre mulheres brancas e negras sozinhas em bancos de imagens digitais. Fonte: Elaboração própria.

Ao final, pode-se comparar os resultados de todos os grupos (homens e mulheres brancas; homens e mulheres negras), como visto a seguir na figura 3 : 


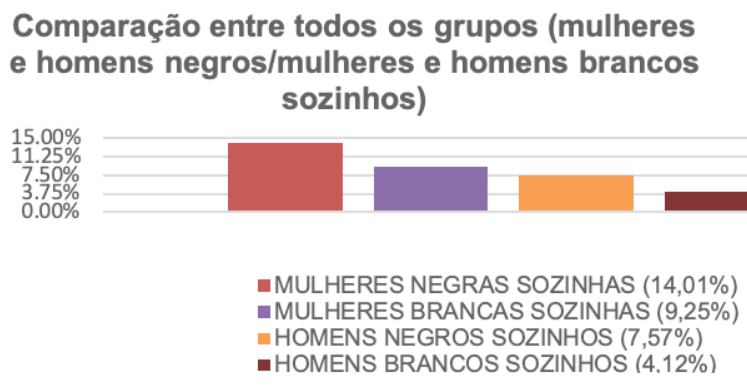

Fig. 3. Quadro comparativo de todos os resultados. Fonte: Elaboração própria.

\section{- Hipótese $B$ :}

Na pesquisa da palavra-chave "white family", serão encontradas mais imagens "infiltradas" de famílias negras, em comparação com imagens "infiltradas" de famílias brancas na busca por "black family".

Essa hipótese parte do pressuposto de que, no contexto da branquitude como normativa e neutralidade, já que "o racismo confere aos brancos a ideia de representantes de uma humanidade desracializada com valores neutros e transparentes" (SCHUCMAN, 2010, p. 48), o termo "white" racializa a busca. O algoritmo entende que a questão da raça foi inserida no interesse de pesquisa, porque a palavra "white" se contrapõe à "black" e, em geral, a pesquisa por "family" já traria predominantemente indivíduos brancos.

\section{- Resultados:}

Aqui, optou-se por analisar a quantidade de famílias negras em sua completude que se "infiltram" como resultado relevante da pesquisa por "white family", assim como quantificar outras raças e etnias, como orientais e latinos, e famílias inter-raciais que também aparecem nestes resultados. Assim:

No banco de imagens Getty Images, das 180 imagens resultantes da palavra-chave "white family", 5 representavam famílias negras e 17 inter-raciais e outras raças; no Shutterstock, das 319 imagens resultantes da palavra-chave "white family", 9 representavam famílias negras e 20 inter-raciais e outras raças; e no Stockphotos, das 301 imagens resultantes da palavra-chave "white family", 11 representavam famílias negras e 28 interraciais e outras raças. Assim, totalizaram 90 imagens de famílias de outras raças em um total de 800 imagens, ou seja, 11,25\%.

No contexto da pesquisa por "black family", por sua vez: no banco de imagens Getty Images, das 180 imagens resultantes da palavra-chave "black family", 1 representou família branca em sua completude e 11 inter-raciais e outras raças; no Shutterstock, das 311 imagens resultantes da palavra-chave "black family", nenhuma representou família 
branca e 4 inter-raciais e outras raças; e no Stockphotos, das 301 imagens resultantes da palavra-chave "black family", 8 representavam famílias brancas e 11 inter-raciais e outras raças. Assim, totalizaram 35 imagens de famílias de outras raças em um total de 792 imagens, ou seja, 4,42\%.

Sendo assim, essa hipótese foi comprovada. O resultado pode ser visto na figura 4.

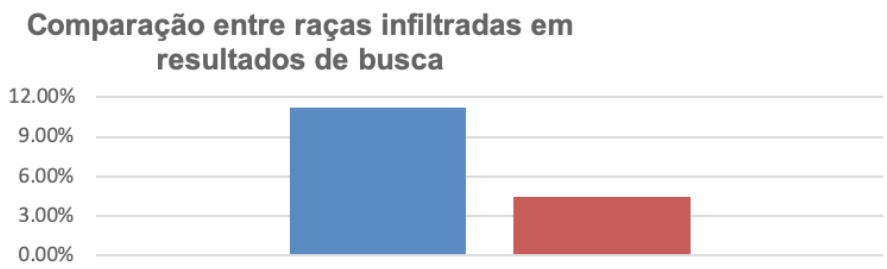

- RAÇAS "INFILTRADAS" NA CATEGORIA "WHITE FAMILY" (11,25\%)

- RAÇAS "INFILTRADAS" NA CATEGORIA "BLACK FAMILY" (4,42\%)

Fig. 4. Quadro comparativo de raças "infiltradas" em resultados de busca - a racialização da branquitude na fórmula algorítmica. Fonte: Elaboração própria.

\section{- Hipótese C:}

Com base na hipótese anterior, a pesquisa pelo termo genérico "family" resultará em maioria de famílias brancas, como representação imagética e algorítmica da hiper-ritualização da neutralidade da branquitude. Nesse tipo de pesquisa, ao não inserir os termos "white" ou "black", o algoritmo entende que a pesquisa é "neutra" e, portanto, oferece resultados que lê como tais.

\section{- Resultados:}

Aqui, também optou-se por quantificar famílias brancas, famílias negras e famílias inter-raciais ou de outras raças e etnias. Dessa forma, no banco de imagens Getty Images, das 300 imagens resultantes da palavra-chave "family", 107 eram famílias totalmente brancas, 24 representavam famílias totalmente negras e 22 famílias inter-raciais e de outras raças; no Shutterstock, das 319 imagens resultantes da palavra-chave "family", 214 eram famílias totalmente brancas, 20 representavam famílias negras e 20 famílias interraciais e de outras raças; e no Stockphotos, das 301 imagens resultantes da palavra-chave "family", 213 eram famílias totalmente brancas, 14 representavam famílias negras e 15 famílias inter-raciais e de outras raças. Assim, da totalidade de 920 imagens de todos os bancos digitais, 534 eram famílias totalmente brancas, isto é, 58,04\% dos resultados; 58 eram famílias totalmente negras, ou seja, 6,30\% dos resultados; e 57 famílias de outras raças ou inter-raciais, ou 6,19\% dos resultados. Algumas imagens não correspondem a nenhuma das variáveis neste caso, como aquelas nas quais é impossível definir a raça dos 
participantes, ilustrações com a mesma característica, adulto absolutamente sozinho ou criança sozinha (uma vez que a pesquisa busca por representações de famílias), objetos e paisagens etc. Estas, nesse caso, totalizaram 29,47\% dos resultados de todos os bancos de imagem.

Essa hipótese também foi comprovada. Os resultados podem ser vistos na figura 5.

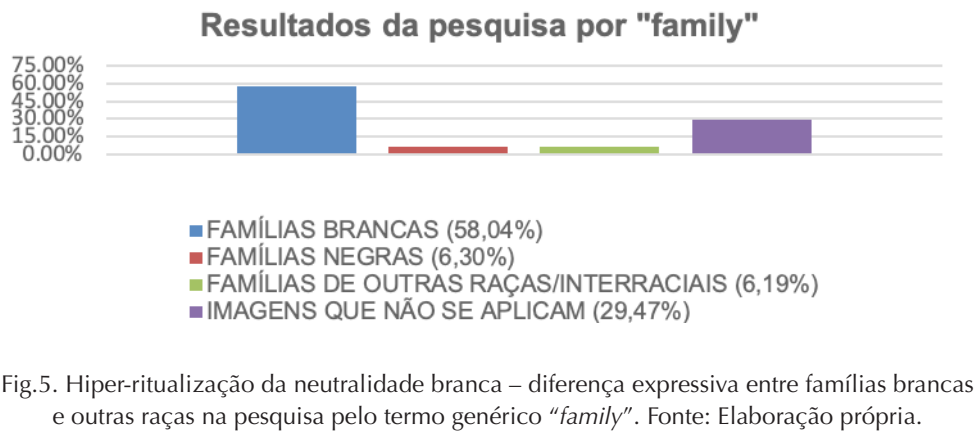

Interessante destacar que o banco de imagens Shutterstock já havia sido questionado a respeito desses resultados pela organização Desabafo Social ${ }^{10}$ em 2017. Com um vídeo intitulado "Vamos conversar, Shutterstock?"11, a organização mostrava como a pesquisa por "família" resultava em maioria de famílias brancas. Para conseguir ter resultados de famílias negras, era preciso expressamente escrever "família negra" na busca. Como resposta, o banco inseriu filtro de etnias em sua busca, fazendo ser possível escolher resultados de pessoas "africanas", "afro-americanas", "negras", "brasileiras", "caucasianas", "chinesas", do "leste asiático" ou "hispânicas"12. No entanto, como pôde ser visto aqui, embora haja a possibilidade agora do filtro, nada foi feito em relação ao algoritmo que atribui à busca genérica "família" a capacidade de resultar em expressiva maioria de indivíduos brancos.

\section{Considerações finais}

Este trabalho realizou uma análise de 2.512 fotografias e ilustrações entre 3 bancos de imagens digitais (Getty Images, Shutterstock e Stockphotos) com o intuito de perceber, especificamente, se os resultados imagéticos atribuídos a famílias negras e brancas obedeciam ao mesmo padrão construtivo. Nesse contexto, buscava-se aqui identificar se, no treinamento algorítmico destes bancos de imagens, as mulheres negras sozinhas eram apresentadas mais sozinhas do que as mulheres brancas, como indício de hiperritualização da solidão da mulher negra.

10 A Desabafo Social é uma organização brasileira realizadora de projetos de empreendedorismo social, formação e produção de conteúdo, utilizando comunicação e novas tecnologias para promover educação em direitos humanos. Sobre a organização: www.desabafosocial.com.br.

11 Ver em: https://youtu.be/tA7MllCbq00.

12 Ver www.shutterstock.com. 
Pôde-se perceber que as imagens consideradas mais "relevantes" (filtro dos próprios sites) associavam a palavra-chave "family" a mulheres negras desacompanhadas com mais frequência do que a mulheres brancas, assim como, adicionalmente, foi percebido que os homens negros também aparecem mais sozinhos que os homens brancos. Nesse sentido, entende-se que há, de fato, hiper-ritualização imagética do preterimento afetivo aos negros, sobretudo à mulher negra, manifestado tanto pelo campo produtivo das imagens quanto pelas escolhas algorítmicas que atribuem relevância a estas representações.

Ademais, o dado das imagens "infiltradas" parece interessante para posterior escrutínio, uma vez que revelou um indício de treinamento algorítmico para a consideração da branquitude como neutra e não como raça. Ou seja, se nos resultados para "black family" quase não há resultados infiltrados de famílias brancas, por que nos resultados para "white family" há tantas imagens de famílias negras? Acredita-se aqui que o termo "white" racializa, para o algoritmo, a busca, já que insere a cor em um contexto no qual a branquitude não se vê como identidade racial (SCHUCMAN, 2010) e sim como normativa e neutralidade. Ora, para encontrar imagens de famílias brancas nestes bancos somente há necessidade de fazer pesquisas genéricas, como "family", como foi corroborado aqui pela comprovação da terceira hipótese.

Nesse sentido, entende-se que o input da raça na palavra "white" só estaria sendo interpretado em sua oposição à palavra "black", pois esta sim estaria associada à racialização. Enquanto nos resultados para "black family", parece haver uma exata interpretação do que seriam famílias negras (talvez porque houve a intencionalidade de introduzir essa definição no código), os resultados para "white family" podem apresentar tamanha infiltração de outras raças porque não houve semelhante intencionalidade. O algoritmo, portanto, entende a palavra white como contraponto racial e, então, apresenta resultados de imagens que, em seu aprendizado, constituem como racializados, isto é, os não-brancos. Essas discussões merecem posterior escrutínio.

Essa percepção de neutralidade para alguns corpos e sujeitos é evidente até mesmo quando há iniciativas de suposta diversificação do portfólio destes bancos de imagens. O Getty Images, por exemplo, em uma parceria com a Dove e a Girlgaze, lançou recentemente o projeto \#ShowUs (\#NosMostre) ${ }^{13}$, apresentando uma coleção específica de imagens mais diversas do público feminino e não-binário. No entanto, o site deixa claro que o projeto se materializa em uma biblioteca de fotografias separada especialmente para a parceria das marcas $^{14}$. Ou seja, não há uma tentativa de transformar todo o desenho político, tecnológico e produtivo do site para que as imagens postas em circulação sejam, de fato, representativas das diversidades corpóreas, raciais e de gênero que compõem o todo social.

13 https://www.gettyimages.com/showus

14 Na página do projeto, a Getty Images afirma "License the photos from Project \#ShowUs for your next project or campaign by searching below or using the \#ShowUs keyword" (Licencie as fotos do Projeto \#NosMostre para seu próximo projeto ou campanha buscando abaixo ou usando a palavra-chave \#NosMostre - tradução nossa), deixando evidente que é preciso buscar pela hashtag para encontrar as fotos. Elas não são encontradas nas buscas gerais. 
Acredita-se, por fim, que há relevância científica nas pesquisas sobre mecanismos de busca e escolhas algorítmicas que ditam os resultados imagéticos que comporão o imaginário social sobre os corpos e sujeitos, mas é fundamental a continuidade do aprofundamento sobre o tema, na tentativa de expor as problemáticas e contribuir para a compreensão das dinâmicas produtivas que direcionam estes agentes artificiais. No caso aqui iniciado, propõe-se como objeto de futuras pesquisas as análises das outras categorias de hiperritualização de gênero, como sugeriu o estudo goffmaniano, mas agora com a inserção da variável raça como determinante para a interpretação dos resultados. Essas iniciativas poderão indicar os padrões construtivos das imagens midiáticas e suas implicações socioculturais, assim como podem expor com nitidez os modos do racismo contemporâneo.

Fernanda Carrera é professora da Escola de Comunicação da Universidade Federal do Rio de Janeiro (UFRJ), do Programa de Pós-graduação em Comunicação da Universidade Federal Fluminense (PPGCOM/UFF) e do Programa de Pós-graduação em Estudos da Mídia da Universidade Federal do Rio Grande do Norte (PPgEM/UFRN). É líder do LIDD - Laboratório de Identidades Digitais e Diversidade (UFRJ). É doutora em Comunicação pela Universidade Federal Fluminense (UFF) e mestre em Comunicação e Cultura Contemporâneas pela Universidade Federal da Bahia (UFBA).

fernanda.carrera@eco.ufrj.br

Denise Carvalho é pós-doutoranda no Programa de Pósgraduação em Estudos da Mídia (PPgEM/UFRN). É doutora em Sociologia pela Universidade de São Paulo (FFLCH/USP) e mestre em Direito pela USP.

denisecarvalho@usp.br

\section{Referências}

ADNER, R. When are technologies disruptive? A demand-based view of the emergence of competition. Strategic Management Journal, v. 23, n. 8, p. 667-688, 2002.

AKOTIRENE, C. O que é interseccionalidade? Letramento, 2018.

AZEVEDO, T. de. As elites de cor: um estudo de ascensão social. São Paulo: Companhia Editora Nacional, 1955.

BAKER, C. N. Images of Women's Sexuality in Advertisements: A Content Analysis of Black- and White-Oriented Women's and Men's Magazines. Sex Roles, v 52, n. 1/2, January 2005. 
CARNEIRO, S. Enegrecer o feminismo: a situação da mulher negra na América Latina a partir de uma perspectiva de gênero. Racismos contemporâneos. Rio de Janeiro: Takano Editora, v. 49, p. 49-58, 2003.

Gênero Raça e Ascensão Social. Revista Estudos Feministas, v. 3, n. 2, p. 544, 1995.

CARRERA, F. Hiper-ritualização de gênero na ciberpublicidade: revisitando Goffman no contexto digital. Anais do XXVII Encontro Anual da Compós, Pontifícia Universidade Católica de Minas Gerais, Belo Horizonte - MG, 05 a 08 de junho de 2018.

CITRON, D. K.; PASQUALE, F. The scored society: due process for automated predictions. Wash. L. Rev., v. 89, p. 1, 2014.

COLLINS, P. Black feminist thought $\left(2^{\text {nd }}\right.$ ed.). New York: Routledge, 2000.

CRENSHAW, K. Demarginalizing the intersection of race and sex: A Black feminist critique of antidiscrimination doctrine, feminist theory, and antiracist politics [1989]. In: Feminist legal theory. Routledge, 2018. p. 57-80.

DATTA, A.; TSCHANTZ, M. C.; DATTA, A. Automated experiments on ad privacy settings. Proceedings on Privacy Enhancing Technologies, v. 2015, n. 1, p. 92-112, 2015.

ELIAS, N. A solidão dos moribundos: seguido de envelhecer e morrer. Trad.: Plínio Dentzien. Rio de Janeiro: Jorge Zahar, 2001.

FORD, J. B. et al. Gender Role Portrayals in Japanese Advertising: A Magazine Content Analysis, Journal of Advertising, 27:1, 113-124, 1998.

GOFFMAN, E. Gender Advertisements. Cambridge, Mass.: Harvard University Press, 1979. 84 pp.

GROSFOGUEL, R. A estrutura do conhecimento nas universidades ocidentalizadas: racismo/sexismo epistêmico e os quatro genocídios/epistemicídios do longo século XVI. Sociedade e Estado, v. 31, n. 1, p. 25-49, 2016.

HARARI, Y. N. Dataism is our new god. New Perspectives Quarterly, v. 34, n. 2, p. 36-43, 2017.

HOBSON, J. Digital Whiteness, primitive Blackness: Racializing the "digital divide" in film and new media. Feminist Media Studies, v. 8, n. 2, p. 111-126, 2008.

HOOKS, B. Intelectuais negras. Estudos Feministas, n. 2, p. 464-478, 1995.

JEWELL, K. From Mammy to Miss America and beyond. New York: Routledge, 1993.

LARSON, J. et al. How we analyzed the COMPAS recidivism algorithm. ProPublica (5 2016), v. 9, 2016.

MALBON, J. E. Geo-Pricing of Digital Media: European and Australian Policy Debates Compared. In: Media Diversity Law: Australia and Germany Compared Gounalakis G and Taylor G (eds.) (Peter Lang Academic Research, Frankfurt 2016).

MCLAUGHLIN, T. L.; GOULET, N. Gender Advertisements in Magazines Aimed at African Americans: A Comparison to Their Occurrence in Magazines Aimed at Caucasians. Sex Roles, v. 40, n. 1/2, 1999.

MOORE, H. L. Fantasias de poder e fantasias de identidade: gênero, raça e violência. Cadernos Pagu, v.14, 2000, p. 13-44.

MOROZOV, E. Digital technologies and the future of data capitalism. Social Europe, p. 23-6, 2015.

NOBLE, S. U. Algorithms of Oppression: how search engines reinforce racism. NYU Press, 2018.

OSOBA, O. A.; WELSER IV, W. An intelligence in our image: the risks of bias and errors in artificial intelligence. Rand Corporation, 2017. 
PACHECO, A. C. L. Mulher negra: afetividade e solidão. Salvador: EDUFBA (Coleção Temas Afro), 2013.

. "Branca para casar, mulata para f... e negra para trabalhar": escolhas afetivas e significados de solidão entre mulheres negras em Salvador, Bahia. Tese de Doutorado em Ciências Sociais: IFCH, Campinas, 2008.

PLOUS, S., \& NEPTUNE, D. Racial and gender biases in magazine advertising: A content analytic study. Psychology of Women Quarterly, 21, 627-644, 1997

SCHUCMAN, L. V. Sim, nós somos racistas: estudo psicossocial da branquitude paulistana. Psicologia \& Sociedade, v. 26, n. 1, p. 11, 2014.

Racismo e antirracismo: a categoria raça em questão. Revista Psicologia Política, v. 10, n. 19, p. 41-55, 2010.

SILVA, Tarcízio. Teoria Racial Crítica e Comunicação Digital: conexões contra a dupla opacidade. Anais do $42^{\circ}$ Congresso Brasileiro de Ciências da Comunicação. Sociedade Brasileira de Estudos Interdisciplinares da Comunicação. Belém, Pará, 2019. São Paulo: Intercom, 2019

SOUZA, C. A. da S. A solidão da mulher negra - sua subjetividade e seu preterimento pelo homem negro na cidade de São Paulo. Dissertação (Mestrado em Ciências Sociais), PUC/SP, São Paulo, 2008.

WEI, C. Research on the stereotype of western women in advertising of Chinese fashion magazines.

China Media Research, 6(2), 25-33, 2010. 